\title{
Produção e qualidade de melão Cantaloupe em cultivo protegido temporariamente com agrotêxtil em Mossoró, Rio Grande do Norte ${ }^{1}$
}

\author{
Francisco Gauberto Barros dos Santos*2, Maria Zuleide de Negreiros ${ }^{3}$, José Francismar de Medeiros ${ }^{4}$, \\ Glauber Henrique de Sousa Nunes ${ }^{4}$, Damiana Cleuma de Medeiros ${ }^{5}$, Leilson Costa Grangeiro ${ }^{4}$
}

http://dx.doi.org/10.1590/0034-737X201562010012

\section{RESUMO}

Desde o ano de 2001, na região do agropolo de Mossoró/Assu-RN, o agrotêxtil é utilizado como proteção de plantas contra pragas da cultura do meloeiro. Este experimento teve como objetivo avaliar a produção e a qualidade de dois híbridos de melão Cantaloupe, em cultivo protegido, temporariamente, com agrotêxtil. O trabalho foi realizado na Horta da Universidade Federal Rural do Semi-Árido (UFERSA), em Mossoró-RN, de julho a outubro de 2010. O delineamento experimental foi de blocos casualizados completos, com quatro repetições, dispostos no esquema de parcelas subdivididas no espaço. As parcelas foram representadas pelo número de dias após o transplante das mudas (DAT), em que as plantas permaneceram sob proteção de agrotêxtil $(0 ; 18 ; 21 ; 24 ; 27$ e $30 \mathrm{DAT})$ e, as subparcelas, por dois híbridos F1 de melão Cantaloupe: 'Acclaim' e 'Caribbean Gold RZ'. Foram avaliadas características de produção e de qualidade. Os tratamentos com proteção temporária com agrotêxtil não afetaram a produtividade total dos dois híbridos; todavia, a firmeza de polpa apresentou aumento crescente, enquanto a acidez total titulável, os açúcares solúveis totais, os sólidos solúveis e o pH apresentaram redução com o aumento do tempo de permanência do agrotêxtil sobre as plantas. O 'Caribbean Gold RZ', em comparação com o 'Acclaim', apresentou maior produtividade comercial para exportação, maior massa média de frutos, mais firmeza de polpa, maior acidez total titulável, maior teor de sólidos solúveis e menor $\mathrm{pH}$.

Palavras-chave: Cucumis melo L., tecido não tecido, TNT, produtividade, proteção de plantas.

\section{ABSTRACT \\ Production and quality of Cantaloupe melon grown in protected cultivation temporarily with row cover in Mossoró, Rio Grande do Norte State, Brazil}

Row cover has been used as protection against pests in Mossoró/Assu agriculture center in the State of Rio Grande do Norte, since 2001. The objective of this experiment was to analyze the yield and quality of two 'Cantaloupe' melon hybrids grown temporarily with row cover in a greenhouse. This study was carried out in the Garden of the Semi-Arid Rural Federal University (Universidade Federal Rural do Semi-Árido - UFERSA) in Mossoró, State of Rio Grande do Norte, from July to October 2010. The experimental design was a complete randomized block with four replications arranged in a split plot in space design. The plots were the number of days after transplant (DAT) when plants remained under row cover protection $(0 ; 18 ; 21 ; 24,27$ and 30 DAT) and the sub plots were two F1 "Cantaloupe" melonhybrids, "Acclaim" and "Caribbean Gold RZ". Yield and quality characteristics were evaluated. The treatments with temporary row cover protection did not affect the total yield of the two hybrids; however, pulp

\footnotetext{
Submetido em 04/10/2012 e aprovado em 17/09/2014.

${ }^{1}$ Parte da tese de Doutorado do primeiro autor.

${ }^{2}$ Instituto de Educação, Ciência e Tecnologia do Ceará, Crato, Ceará, Brasil. gaubertob@gmail.com

${ }^{3}$ Universidade Federal Rural do Semi-árido, Núcleo de Pós-Graduação em Fitotecnia, Mossoró, Rio Grande do Norte, Brasil. zuleide@ufersa.edu.br

${ }^{4}$ Universidade Federal Rural do Semi-Árido, Núcleo de Pós-Graduação em Fitotecnia, Mossoró, Rio Grande do Norte, Brasil. jfmedeir@ufersa.edu.br

${ }^{5}$ Escola Agrícola de Jundiaí, Macaíba, Rio Grande do Norte, Brasil. damianacm@ hotmail.com

*Autor para correspondência: gaubertob@gmail.com
} 
firmness continuously increased whereas total titratable acidity, total soluble sugar, total soluble solids and $\mathrm{pH}$ reduced as permanence time of row cover on the plants increased. "Caribbean Gold RZ" yield presented higher commercial productivity for export, higher average fruit weight, higher pulp firmness, higher total titratable acidity and higher content of soluble solids and lower $\mathrm{pH}$ than "Acclaim" melons.

Key words: Cucumis melo L., nonwoven fabric, plant protection, TNT, yield.

\section{INTRODUÇÃO}

A tendência do mercado é o aumento da demanda por melões do grupo Cantalupensis, aromáticos, de polpa cor salmão, maior teor de sólidos solúveis, sendo que esses frutos têm apresentado expressiva expansão nos polos agrícolas de Mossoró/Assu-RN e do Vale do JaguaribeCE (Medeiros et al., 2007). Vários híbridos de melão Cantaloupe são plantados e comercializados pelos produtores do Agropolo Mossoró/Assu e, entre eles, estão: 'Sedna', 'Torreon', 'Acclaim', 'Vera Cruz', 'Mirage', 'Coronado', 'Cristóvão', 'Imperial 45', 'Cristobal', 'Magellan', 'PS4048' (longa vida), 'Hy-Mark', 'Caribbean Gold RZ', 'Don Luís' e 'M2-308' (Moreira et al., 2009).

O melhor desempenho agronômico de uma espécie cultivada pode ser obtido pelo aprimoramento de técnicas de cultivo ou de introdução de novas tecnologias: neste contexto, uma prática que vem sendo utilizada no Agropolo de Mossoró/Assu, desde 2001, é o uso do agrotêxtil branco em meloeiro e melancieira (Medeiros $e t$ al., 2008).

O agrotêxtil é confeccionado a partir de longos filamentos de polipropileno que são colocados em camadas e soldados entre si por temperaturas apropriadas, constituindo-se num material leve e de resistência suficiente para sua utilização na agricultura (Barros Junior $e t$ al., 2004). No agropolo de Mossoró/Assu -RN, o agrotêxtil é colocado sobre as mudas recém-transplantadas, na forma de túnel baixo, até o início da floração do meloeiro, com o objetivo de reduzir, principalmente, a infestação de mosca branca (Bemisia tabaci) e de mosca minadora (Lyriomyza spp.). Esses dois insetos têm causado sérios danos à produção e à qualidade dos frutos, elevando os custos de produção, tanto com o uso de mão de obra quanto com a aplicação de defensivos (Medeiros et al., 2008)

No Brasil, são poucos os trabalhos que avaliaram o comportamento de genótipos de melão, quando submetidos à retirada do agrotêxtil, em diferentes etapas do desenvolvimento das plantas, tanto para características quantitativas quanto qualitativas, podendo ser citados trabalhos desenvolvidos em outros países, como México e Austrália (Ibarra-Jiménez et al., 2000; Ibarra et al., 2001; Long et al., 2004).
Nas condições de Saltillo, Coahuila, México, o mulching de polietileno preto isolado e, ou, em combinação com a proteção da parte aérea do melão cv. 'Crusier', com agrotêxtil, por até 10; 20 e 32 dias após o plantio, resultou em plantas mais precoces, com maior rendimento comercial e total, em relação aos do controle (Ibarra et al., 2001). Para estas características, não foi observada diferença entre os tratamentos com mulching na presença ou ausência da proteção da parte aérea com agrotêxtil.

Além do controle de pragas, a utilização do agrotêxtil pode servir para alterar provisoriamente a relação fontedreno do meloeiro, por atraso da polinização dessa espécie. Long et al. (2004), na Austrália, trabalhando com o atraso da polinização do meloeiro, com a utilização do agrotêxtil, constataram que esse método permite à planta investir os fotoassimilados disponíveis no crescimento vegetativo e, posteriormente, na fixação de maior número de frutos por planta, alterando a relação fonte-dreno, a produção e a qualidade dos frutos. Foi observado aumento da biomassa dos frutos, contudo, sem aumento do teor de sólidos solúveis.

O objetivo deste trabalho foi avaliar a produção e a qualidade de frutos dos híbridos de melão Cantaloupe 'Caribbean Gold RZ' e 'Acclaim', em cultivo protegido temporariamente com agrotêxtil, em Mossoró, RN.

\section{MATERIAL E MÉTODOS}

O experimento foi realizado na Horta do Departamento de Ciências Vegetais da Universidade Federal Rural do Semi-Árido (UFERSA), Mossoró-RN ( $5^{\circ} 11^{\text {' }}$ $\mathrm{S}, 37^{\circ} 20^{\prime} \mathrm{W}$, a $18 \mathrm{~m}$ de altitude), de 22 de julho a 5 de outubro de 2010. O clima da região, de acordo com a classificação climática de Köppen, é do grupo "BSwh" (Pereira et al., 2010) e o solo foi classificado como Argissolo Vermelho-Amarelo eutrófico abrupto (Santos et al., 2006).

O delineamento experimental adotado foi o de blocos casualizados completos, com quatro repetições. Os tratamentos foram dispostos no esquema de parcelas subdivididas no espaço, sendo as parcelas representadas pelo número de dias, após o transplante das mudas (DAT), 
que as plantas permaneceram cobertas com agrotêxtil branco $(0 ; 18 ; 21 ; 24 ; 27$ e 30 DAT) e, as subparcelas, por dois híbridos F1 de melão Cantaloupe: 'Acclaim' e 'Caribbean Gold RZ'. Cada subparcela ocupou uma área total de $60,0 \mathrm{~m}^{2}$, com $8 \mathrm{~m}$ de largura e 7,5 $\mathrm{m}$ de comprimento, no espaçamento $2,0 \mathrm{~m}$ x $0,3 \mathrm{~m}$, comportando quatro fileiras de plantas. A área útil da subparcela foi de 27,6 $\mathrm{m}^{2}$ (6,9 m x $\left.4 \mathrm{~m}\right)$, constituída das duas fileiras centrais, sem bordaduras, totalizando 46 plantas.

O preparo do solo consistiu em uma gradagem e sulcamento em linhas, espaçadas de 2,0 m e com profundidade de $0,2 \mathrm{~m}$, em que foi realizada a adubação de fundação com o composto orgânico polifértil ${ }^{\circledR}$, correspondente a 7,5 t ha ${ }^{-1}$, e, posteriormente, levantados os camalhões para plantio das mudas.

Utilizou-se sistema de irrigação por gotejamento, com linhas laterais de polietileno de $16 \mathrm{~mm}$, com emissores integrados espaçados em $0,3 \mathrm{~m}$, com vazão de $1,5 \mathrm{~L} \mathrm{~h}^{-1}$, para uma pressão de serviço de $100 \mathrm{KPa}$.

A cobertura do solo foi feita com o filme de polietileno dupla face (preto e prateado); em seguida, foram colocados arcos de polietileno rígido reciclado, para sustentação do agrotêxtil, com uma altura de $40 \mathrm{~cm}$ do solo na parte central do arco. As mudas, produzidas em bandejas de poliestireno com 128 células, foram transplantadas no dia 2 de agosto de 2010, aos 12 dias após a semeadura, quando a segunda folha verdadeira apresentava-se completamente expandida. Em seguida, procedeu-se à cobertura das plantas com o agrotêxtil, ou TNT (tecido não tecido), com exceção das parcelas-testemunha que permaneceram descobertas. Utilizou-se agrotêxtil com gramatura de $15 \mathrm{~g} \mathrm{~m}^{-2}$ e largura de $1,40 \mathrm{~m}$, sendo fixado, nas extremidades, com solo.

Durante o ciclo da cultura, foram utilizados $296,63 \mathrm{~mm}$ de lâmina total de irrigação. Essa lâmina foi determinada de acordo com a evapotranspiração da cultura (Etc) para cultivo convencional, estimada pela metodologia do Kc dual, segundo Allen et al. (2006), considerando-se o Kc basal para fase intermediária de 0,85 e, para a fase final do ciclo, de 0,7 , com eficiência de aplicação da irrigação de $91 \%$.

A adubação de fundação foi feita apenas com composto orgânico e, a adubação de cobertura, realizada, exclusivamente, por fertirrigação com injetor tipo Venturi. Durante o ciclo da cultura, foram utilizados 90 $\mathrm{kg} \mathrm{ha}^{-1}$ de N, $70 \mathrm{~kg} \mathrm{ha}^{-1}$ de $\mathrm{P}_{2} \mathrm{O}_{5}$ e $120 \mathrm{~kg} \mathrm{ha}^{-1}$ de $\mathrm{K}_{2} \mathrm{O}$. As fontes de fertilizantes foram: ureia, monoamônio fosfato (MAP) purificado, cloreto de potássio, sulfato de magnésio, nitrato de cálcio e ácido nítrico, além de micronutrientes.

O controle de pragas e doenças foi feito de acordo com as recomendações convencionais; foi realizado monitoramento a cada três dias, observando-se o dano econômico causado por mosca branca (Bemisia tabaci) e mosca minadora (Lyriomyza spp.), conforme Braga Sobrinho et al.(2003). O controle de plantas daninhas foi realizado com enxadas, entre os camalhões das parcelas, e, manualmente, entre as plantas.

O ponto de colheita adotado foi o indicado para os híbridos utilizados no trabalho, que corresponde à mudança de coloração da casca, de verde escuro para verde claro, e ao início da formação da camada de abscisão na base do pedúnculo.

A colheita dos frutos foi iniciada aos 68 dias após a semeadura, sendo realizadas cinco colheitas, com intervalos de dois dias. Para as avaliações de qualidade, foram amostrados três frutos de cada repetição, da segunda e quarta colheitas, e levados ao laboratório de PósColheita do Departamento de Ciências Vegetais da UFERSA.

Para as características de produção, foram avaliados produtividades total (PT), comercial para exportação (FCEX), comercial para mercado interno (PCIN), não comercial (PNC) ou refugos $\left(\mathrm{t} \mathrm{ha}^{-1}\right)$, número de frutos por planta e massa média de frutos $(\mathrm{g})$.

Foram considerados comerciais frutos que se apresentavam firmes, uniformes quanto à cor, com bom rendilhamento de casca, sem deformações, murchamento, rachaduras, sinais de podridão, ataques de insetos ou pragas e danos mecânicos.

A seleção de frutos baseou-se em informações fornecidas por empresa de grande porte, localizada em Mossoró-RN, além de nas qualidades externas anteriormente mencionadas, e adotou-se como parâmetro, para diferenciar frutos destinados aos mercados externo e interno, a presença do pedúnculo no fruto (mercado externo) ou frutos destalados (mercado interno).

Os frutos que não se enquadraram na classificação anterior foram considerados não comerciais ou refugos, ou seja, os frutos praguejados, acometidos de doenças, deformados, com podridão apical, rachados, com queimaduras de sol e com massa média inferior a $550 \mathrm{~g}$.

Para as características de qualidade, foram avaliados firmeza de polpa, teor de sólidos solúveis, acidez titulável, açúcares solúveis totais e $\mathrm{pH}$. A firmeza dos frutos foi obtida utilizando-se um penetrômetro manual. Os resultados foram obtidos em $\mathrm{lb} \mathrm{pol}^{-2}$ e convertidos para Newton (N) multiplicando-se por 4,45. Os teores de sólidos solúveis (SS) foram determinados no suco, usando-se um refratômetro digital com correção automática de temperatura, com os resultados expressos em \%. A acidez titulável (AT) foi obtida por titulação do suco com solução de $\mathrm{NaOH}$ 0,1 N e expressa como percentagem de ácido cítrico - \%AC (Instituto Adolfo Lutz, 1985). A relação sólidos solúveis e acidez titulável (SS/AT) e os açúcares solúveis totais (AST) foram quantificados por meio do 
método Antrona, conforme Yemn \& Willis (1954), e expressos em \%. O pH foi determinado com potenciômetro digital com membrana de vidro, calibrado com soluções tampão $\mathrm{pH}$ 4,0 e pH 7,0. Todas essas avaliações foram realizadas em amostras retiradas na porção mediana e das duas extremidades de uma fatia de cada fruto.

Os dados obtidos foram submetidos às análises de variância $e$, as médias dos tratamentos, comparadas às do controle pelo teste Dunnett a 5\% de probabilidade, com o software SISVAR. As regressões polinomiais ao longo dos dias de cobertura com agrotêxtil (TNT), foram obtidas obedecendo-se o nível de significância de 5\% de probabilidade, pelo teste F, com o software do Table Curve 2D v5.01 (Jandel Scientific, 1991).

\section{RESULTADOS E DISCUSSÃO}

Não houve interação significativa entre os dias após o transplante, que as mudas passaram cobertas com agrotêxtil (TNT), e cultivares (C) e tampouco para o TNT para nenhum dos componentes da produção (Tabela 1). Porém, quanto ao fator cultivar (C), com exceção da produtividade total (PT) e massa média de frutos não comerciais (MMFNC), houve diferença significativa para os demais componentes de produção (Tabela 2).

Apesar de, neste trabalho, não ter sido encontrado efeito significativo da proteção temporária da parte aérea do meloeiro com agrotêxtil, em trabalhos realizados por outros pesquisadores, no México e no Brasil, inclusive na região nordeste, foram obtidos incrementos na produção. Assim, no México, a proteção temporária da parte aérea do melão cv. 'Crusier' com agrotêxtil, até 10, 20 e 32 dias após o plantio, isolado e, ou, em combinação com o mulching de polietileno preto, resultou em plantas mais precoces, com maiores rendimentos comercial e total, em relação aos da testemunha (Ibarra et al., 2001).

Em Juazeiro-BA, o aumento de produção de frutos tipo 6 (seis frutos por caixa) e da massa fresca de frutos foi observado, em melão amarelo 'AF $682^{\circ}$ ', com a proteção temporária da parte aérea com agrotêxtil, por até 30 dias após o plantio (Dias et al., 2006).

Em Baraúna/RN, Medeiros et al. (2007) verificaram aumentos de 20,96, 12,96 e 16,43\%, respectivamente, no número de frutos para mercado externo, comerciais e totais, e redução de $31,30 \%$ no número de frutos para mercado interno, em melão 'Torreon ' protegido com agrotêxtil, até 28 dias após o transplante.

Embora os dois cultivares não tenham diferido quanto à produtividade total, a produtividade comercial para exportação, do híbrido Caribbean Gold RZ (27,02 t ha1) foi $88,03 \%$ superior, enquanto a produtividade comercial para o mercado interno (PCIN), e produtividade não comercial (PNC) do 'Acclaim' foram, respectivamente, $1.470,37$ e $186,47 \%$ maiores que as do 'Caribean Gold' (Tabela 2).

O 'Caribbean Gold RZ' também apresentou maior número de frutos comerciais para exportação por planta (FCEX), maior massa média de frutos totais e comerciais, enquanto, o 'Acclaim', maiores números de frutos totais (FT), comerciais para o mercado interno (FRCIN) e não comerciais (FNC) (Tabela 2).

Uma das razões para a maior produção de frutos comerciais para exportação, do cultivar 'Caribean Gold

Tabela 1. Valores médios de produtividades total (PT), comercial exportação (PCEX), comercial mercado interno (PCIN), não comercial (PNC), frutos totais por planta (FT), frutos comerciais para exportação por planta (FCEX), frutos para mercado interno por planta (FRCIN), frutos não comerciais por planta (FNC), massa média de frutos totais (MMFT), frutos comerciais (MMFC) e frutos não comerciais (MMFNC) de melão Cantaloupe sob proteção com agrotêxtil (TNT) até diferentes dias após o transplantio das mudas (DAT)

\begin{tabular}{|c|c|c|c|c|c|c|c|c|}
\hline \multirow{2}{*}{ Característica } & \multicolumn{6}{|c|}{ Proteção com TNT até DAT } & \multirow{2}{*}{$\mathbf{F}_{\mathrm{TNT}}$} & \multirow{2}{*}{$\mathrm{CV}(\%)_{\mathrm{TNT}}$} \\
\hline & $\mathbf{0}$ & 18 & 21 & 24 & 27 & 30 & & \\
\hline PT (t ha-1) & 31,18 & 28,32 & 32,07 & 27,45 & 28,45 & 30,44 & $0,92^{\text {ns }}$ & 18,34 \\
\hline $\operatorname{PCEX}\left(\mathrm{t} \mathrm{ha}^{-1}\right)$ & 22,28 & 19,45 & 21,30 & 21,07 & 19,64 & 20,42 & $0,46^{\mathrm{ns}}$ & 21,52 \\
\hline $\operatorname{PCIN}\left(\mathrm{t} \mathrm{ha}^{-1}\right)$ & 3,79 & 4,15 & 6,01 & 2,54 & 4,51 & 4,45 & $1,81^{\mathrm{ns}}$ & 55,85 \\
\hline PNC $\left(\mathrm{t} \mathrm{ha}^{-1}\right)$ & 5,12 & 4,71 & 4,76 & 3,83 & 4,29 & 5,57 & $0,73^{\text {ns }}$ & 42,57 \\
\hline FT ( planta $\left.^{-1}\right)$ & $1,68^{1}$ & 1,65 & 1,66 & 1,60 & 1,64 & 1,68 & $0,84^{\mathrm{ns}}$ & 6,21 \\
\hline FCEX $\left(\right.$ planta $\left.^{-1}\right)$ & $1,48^{1}$ & 1,41 & 1,43 & 1,43 & 1,42 & 1,43 & $0,65^{\mathrm{ns}}$ & 5,48 \\
\hline FRCIN (planta ${ }^{-1}$ ) & $1,09^{1}$ & 1,12 & 1,14 & 1,08 & 1,13 & 1,12 & $1,06^{\mathrm{ns}}$ & 5,88 \\
\hline FNC (planta $\left.{ }^{-1}\right)$ & $1,21^{1}$ & 1,20 & 1,18 & 1,14 & 1,17 & 1,21 & $1,27^{\mathrm{ns}}$ & 5,54 \\
\hline MMFT (kg) & 1,03 & 0,99 & 1,09 & 1,09 & 1,09 & 1,01 & $1,59^{\mathrm{ns}}$ & 9,05 \\
\hline MMFC (kg) & 1,11 & 1,13 & 1,19 & 1,19 & 1,17 & 1,12 & $1,04^{\mathrm{ns}}$ & 8,96 \\
\hline MMFNC (kg) & 0,67 & 0,57 & 0,73 & 0,77 & 0,71 & 0,65 & $1,67^{\mathrm{ns}}$ & 22,58 \\
\hline
\end{tabular}

$\stackrel{1}{\prime}$ Médias dos dados transformados em $\sqrt{\mathrm{x}+1}$

ns Não significativo. * Significativo pelo teste $\mathrm{F}$ de Snedecor a $5 \%$ de probabilidade. ${ }^{* *}$ Significativo pelo teste $\mathrm{F}$ de Snedecor a $1 \%$ de probabilidade.

Rev. Ceres, Viçosa, v. 62, n.1, p. 093-100, jan/fev, 2015 
RZ', foi a maior persistência do pedúnculo dos frutos desse cultivar.

Segundo Duarte \& Peil (2010), o meloeiro tem limites em sua capacidade produtiva e, quando os assimilados são usados no sentido de aumentar o número de frutos fixados por planta, há consequente redução da massa média dos frutos. A massa média dos frutos é componente relevante da produção, além de ser a melhor maneira de exprimir, indiretamente, o tamanho dos frutos (Gualberto et al., 2002).

Com relação às características de qualidade, foi observada interação significativa entre o número de dias em que as plantas ficaram protegidas com agrotêxtil (TNT) x cultivares (C), para açúcares solúveis totais (AST) (Tabela 3). Houve efeito significativo do fator
TNT sobre a firmeza da polpa (FIRM), a acidez titulável (AT), os açúcares solúveis totais (AST) e a relação sólidos solúveis/acidez titulável (SS/AT) (Tabela 3). Para o fator cultivar, ocorreu efeito significativo para todas as características, com exceção da relação SS/AT (Tabela 4).

A firmeza da polpa de frutos (FIRM) aumentou à medida que se retardou (DAT) a retirada do TNT (Figura 1A), indicando que frutos mais firmes foram os provenientes de plantas que permaneceram por mais tempo sob proteção do TNT. A firmeza de frutos variou de 23,99 $\mathrm{N}$ (testemunha) a 32,44 N (30 DAT), sendo que somente os tratamentos em que as plantas permaneceram por mais tempo com o TNT (27 e 30 DAT) foram superiores à testemunha (Tabela 3).

Tabela 2. Valores médios de produtividades total (PT), comercial exportação (PCEX), comercial mercado interno (PCIN), não comercial (PNC), números de frutos totais por planta (FT), frutos comerciais para exportação por planta (FCEX), frutos para mercado interno por planta (FCIN), frutos não comerciais por planta (FNC), massas médias de frutos totais (MMFT), frutos comerciais (MMFC) e de frutos não comerciais (MMFNC) de melão 'Acclaim' (AC) e 'Caribbean Gold RZ' (CAR) cultivados sob proteção de agrotêxtil

\begin{tabular}{|c|c|c|c|c|}
\hline \multirow{2}{*}{ Característica } & \multicolumn{2}{|c|}{ Cultivares } & \multirow{2}{*}{$\mathbf{F}_{\text {cultivar }}$} & \multirow{2}{*}{$\mathrm{CV}(\%)_{\text {cultivar }}$} \\
\hline & $\mathrm{AC}$ & CAR & & \\
\hline PT $\left(\mathrm{t} \mathrm{ha}^{-1}\right)$ & $29,30 \mathrm{a}$ & $30,0 \mathrm{a}$ & $0,27^{\mathrm{ns}}$ & 15,67 \\
\hline $\operatorname{PCEX}\left(\mathrm{t} \mathrm{ha} \mathrm{h}^{-1}\right)$ & $14,37 \mathrm{~b}$ & $27,02 \mathrm{a}$ & $88,80 * *$ & 22,48 \\
\hline $\operatorname{PCIN}\left(\mathrm{t} \mathrm{ha}^{-1}\right)$ & $7,94 \mathrm{a}$ & $0,54 \mathrm{~b}$ & $138,28 * *$ & 51,43 \\
\hline PNC (t ha-1) & $6,99 a$ & $2,44 \mathrm{~b}$ & $75,61 * *$ & 38,48 \\
\hline FT $\left(\right.$ planta $\left.^{-1}\right)$ & $1,69 \mathrm{a}^{1}(1,85)$ & $1,62 \mathrm{~b}(1,61)$ & $10,59 * *$ & 4,57 \\
\hline FCEX $\left(\right.$ planta $\left.^{-1}\right)$ & $1,33 b^{1}(0,78)$ & $1,54 \mathrm{a}(1,37)$ & $66,70 * *$ & 6,05 \\
\hline FCIN ( planta $\left.^{-1}\right)$ & $1,21 \mathrm{a}^{1}(0,48)$ & $1,02 \mathrm{~b}(0,04)$ & $149,54 * *$ & 4,95 \\
\hline FNC $\left(\right.$ planta $\left.^{-1}\right)$ & $1,26 \mathrm{a}^{1}(0,59)$ & $1,11 \mathrm{~b}(0,23)$ & $72,51 * *$ & 5,23 \\
\hline MMFT (kg) & $0,95 \mathrm{~b}$ & $1,11 \mathrm{a}$ & $32,84 * *$ & 9,36 \\
\hline (MMFC) (kg) & $1,11 \mathrm{~b}$ & $1,19 \mathrm{a}$ & $4,67 *$ & 10,86 \\
\hline (MMFNC) (kg) & $0,72 \mathrm{a}$ & $0,65 \mathrm{a}$ & $2,57^{\mathrm{ns}}$ & 20,15 \\
\hline
\end{tabular}

느édias dos dados transformados em Raiz quadrada de $\mathrm{x}+1$. Médias entre parênteses correspondem aos valores não transformados.

ns Não significativo. * Significativo pelo teste F de Snedecor a 5\% de probabilidade. ${ }^{* *}$ Significativo pelo teste F de Snedecor a $1 \%$ de probabilidade.

Tabela 3. Valores médios de firmeza da polpa (FIRM), acidez titulável (AT), sólidos solúveis (SS), relação sólidos solúveis/acidez titulável (SS/AT) e açúcares solúveis totais (AST) de frutos de melão 'Acclaim' e 'Caribbean Gold RZ' sob proteção com agrotêxtil em diferentes dias após o transplantio das mudas (DAT)

\begin{tabular}{lcccccc}
\hline \multirow{2}{*}{ DAT } & FIRM $(\mathbf{N})$ & AT $(\%)$ & SS $(\%)$ & SS/AT & \multicolumn{2}{c}{ AST(\%) } \\
\hline $0^{1}$ & & & & & Acclaim & Caribbean Gold \\
18 & 23,99 & 0,20 & 9,26 & 47,70 & 6,94 & 7,54 \\
21 & $27,53^{\mathrm{ns}}$ & $0,20^{\mathrm{ns}}$ & $9,85 \mathrm{~ns}$ & $49,18^{\mathrm{ns}}$ & $7,98^{\mathrm{ns}}$ & $8,57^{\mathrm{ns}}$ \\
24 & $27,46^{\mathrm{ns}}$ & $0,22^{\mathrm{ns}}$ & $10,33^{\mathrm{ns}}$ & $47,82^{\mathrm{ns}}$ & $7,44^{\mathrm{ns}}$ & $8,57^{\mathrm{ns}}$ \\
27 & $29,34^{\mathrm{ns}}$ & $0,18^{\mathrm{ns}}$ & $9,68 \mathrm{~ns}$ & $55,70^{\mathrm{ns}}$ & $5,08^{*}$ & $8,18^{\mathrm{ns}}$ \\
30 & $32,60^{*}$ & $0,20^{\mathrm{ns}}$ & $9,24 \mathrm{~ns}$ & $47,91^{\mathrm{ns}}$ & $5,14^{*}$ & $6,67^{\mathrm{ns}}$ \\
\hline $\mathrm{F}_{\mathrm{TNT}}$ & $32,44^{*}$ & $0,15^{*}$ & $9,11 \mathrm{~ns}$ & $60,76^{*}$ & $5,03^{*}$ & $6,59^{\mathrm{ns}}$ \\
\hline $\mathrm{CV}(\%)_{\mathrm{TNT}}$ & $3,71^{*}$ & $5,30^{* *}$ & $2,82^{*}$ & $6,05^{* *}$ & & $10,35^{* *}$ \\
\hline
\end{tabular}

$\mathrm{F}_{\mathrm{TNT}}{ }^{\mathrm{ns}}$ Não significativo. ${ }^{* *}$ Significativo pelo teste $\mathrm{F}$ de Snedecor a $1 \%$ de probabilidade

ns Não significativo. *Médias significativamente diferentes da Testemunha ( ${ }^{1}$ Sem TNT durante todo o ciclo - Nível 0) pelo teste de Dunnett a $5 \%$ de probabilidade. 
A firmeza é uma característica importante para exportação de frutos, pois, com o avanço do amadurecimento, ocorre diminuição da firmeza, tornando os frutos mais susceptíveis aos danos mecânicos. Alves et al. (2000) afirmaram que, no momento da colheita do melão, o valor da firmeza da polpa, recomendada para atender as exigências dos mercados exportadores, é de 30 N. Os resultados encontrados neste trabalho $(23,99 \mathrm{~N}$, para testemunha, e 32,44 N, para TNT 30 DAT), superaram os alcançados por Medeiros et al. (2011) e Melo et al. (2012), que obtiveram médias de firmeza da polpa, para melão Cantaloupe, de 25,85 N ('Sedna'), e 15,96 $\mathrm{N}$, para os cultivares 'Bônus no 2' 'Louis' e 'Fantasy'.

A acidez titulável (AT) diminuiu linearmente com a permanência do TNT (Figura 1B), sendo que a da testemunha (0 DAT) foi superior em 33,33\% à do tratamento de 30 DAT (Tabela 3 ). Vale salientar que a maioria dos frutos do controle alcançou maturação mais cedo que os dos tratamentos que ficaram sob proteção do agrotêxtil por mais tempo. O mais comum a ocorrer durante o amadurecimento dos frutos é a perda da acidez, mas, em alguns casos, há um pequeno aumento dos valores com o avanço da maturação (Chitarra \& Chitarra, 2005).

O teor de sólidos solúveis (SS) apresentou resposta quadrática, com máximo estimado de 10,02\%, aos 19 DAT de permanência do TNT (Figura 1C). Assim, a redução estimada de SS, de 10,02 para 8,98\% (30 DAT), promoveu uma diminuição estimada de $10,38 \%$. Não foi verificada variação significativa da característica $S S$, independentemente do tempo em que as plantas permaneceram sob a proteção da manta, em relação à da testemunha, sem TNT (Tabela 3).

O teor de SS é usado como parâmetro de qualidade na classificação de melões Cantaloupe pelo USDA (United States Departament of Agriculture) e os teores encontrados neste trabalho estão dentro da faixa aceitável para comercialização no mercado americano, que seria de 8 a 10\% (Dull et al., 1992), como também para o mercado europeu, que exige conteúdo médio de SS acima de 9\% (Menezes et al., 2000). Resultado de SS médio de $10,11 \%$, para o 'Acclaim', foi verificado por Dantas et al. (2011), avaliando características de qualidade de híbridos de melão Cantaloupe, em Baraúna-RN.

Considerando-se a relação sólúveis/acidez total titulável (SS/AT), nenhum modelo foi ajustado para explicar o comportamento desta característica, em função de DAT de permanência das plantas sob a proteção do TNT (Figura 1D). Para esta característica, a proteção do TNT por 30 DAT superou a testemunha em 32,39\% (Tabela 3).

A quantificação da relação entre o teor de sólidos solúveis e a acidez titulável está relacionada com o balanço entre açúcares e ácidos presentes nos frutos, sendo importante indicativo de sabor. Esses valores tenderam a aumentar de acordo com a redução de ácidos que ocorreu com o amadurecimento dos frutos (Souza, 2006).

Paes (2011), trabalhando com agrotêxtil e mulching em melões Inodorus 'Goldex' e 'Mandacaru', em 2008, no município de Baraúna-RN, não observou efeito significativo das malhas sobre as características SS, AT, SS/ AT e FIRM.

Com o aumento do tempo (DAT) de permanência do agrotêxtil, observou-se decréscimo no teor de açúcares solúveis totais (AST), tanto para o híbrido 'Acclaim' quanto para o 'Caribbean Gold RZ'. No híbrido 'Acclaim', as reduções estimadas foram de 15,04; 26,33; 35, 10 e 42,12 $\%$, e, no 'Caribbean Gold RZ', de 7,16; 13,81; 19,98 e $25,71 \%$, com o atraso de 18 DAT para 21; 24; 27 e 30 DAT, respectivamente (Figura 1E). Também ocorreu pequena diminuição do $\mathrm{pH}$ com o tempo de cobertura com agrotêxtil (Figura 1 F). De acordo com Chitarra \& Chitarra (2005), os açúcares solúveis totais (AST) presentes em frutos constituem de 65 a $85 \%$ do teor de sólidos solúveis, fato que pode explicar a diminuição de SS (Figura $1 \mathrm{C}$ ).

Para a característica AST, o tratamento controle do 'Acclaim' foi superior aos tratamentos sob proteção do agrotêxtil aos 24; 27 e 30 DAT. Entretanto, para o 'Caribbean Gold RZ' não se verificou diferença significativa entre a testemunha e os demais tratamentos (Tabela 3).

O híbrido 'Caribbean Gold RZ' (Cantaloupe americano tipo "Harper”), comparado com o 'Acclaim', apresentou maiores firmeza da polpa e acidez titulável e menor $\mathrm{pH}$ (Tabela 4), indicando que preenche requisitos

Tabela 4. Valores médios firmeza da polpa (FIRM), acidez titulável (AT), sólidos solúveis (SS), relação sólidos solúveis/acidez titulável (SS/AT), açúcares solúveis totais (AST) e pH de frutos de melão ‘Acclaim' (AC) e 'Caribbean Gold RZ' (CAR) cultivados sob proteção de agrotêxtil

\begin{tabular}{lcccc}
\hline \multirow{2}{*}{ Característica } & \multicolumn{2}{c}{ Cultivares } & \multirow{2}{*}{ F $_{\text {cultivar }}$} & CV( \%) \\
\cline { 2 - 3 } & AC & CAR & $45,91^{* *}$ & 12,15 \\
FIRM (N) & $25,46 \mathrm{~b}$ & $32,32 \mathrm{a}$ & $17,82^{* *}$ & 13,39 \\
AT (\%) & $0,16 \mathrm{~b}$ & $0,21 \mathrm{a}$ & $31,02^{* *}$ & 8,40 \\
SS (\%) & $8,93 \mathrm{~b}$ & $10,22 \mathrm{a}$ & $1,50^{\text {ns }}$ & 14,44 \\
SS/AT (\%) & 55,94 & 51,00 & $10,54^{* *}$ & 3,24 \\
pH & $6,97 \mathrm{a}$ & $6,76 \mathrm{~b}$ & \\
\hline
\end{tabular}

ns Não significativo. ${ }^{* *}$ Significativo pelo teste F de Snedecor a $1 \%$ de probabilidade.

Rev. Ceres, Viçosa, v. 62, n.1, p. 093-100, jan/fev, 2015 
importantes para frutos destinados ao mercado externo, que é mais exigente quanto a essas características.

As características firmeza de polpa superior a $30 \mathrm{~N}$ e SS maior que $10 \%$, que atendem as exigências, tanto do mercado Americano quanto do Europeu, qualificam o 'Caribean Gold RZ' como promissor para cultivo na região de Mossoró-Assu.

O híbrido 'Acclaim', com do teor de SS abaixo de $9 \%$ e firmeza média de $25,46 \mathrm{~N}$, observados neste trabalho (Tabela 4), além do elevado número de frutos destalados, é indicado para o mercado interno a granel.
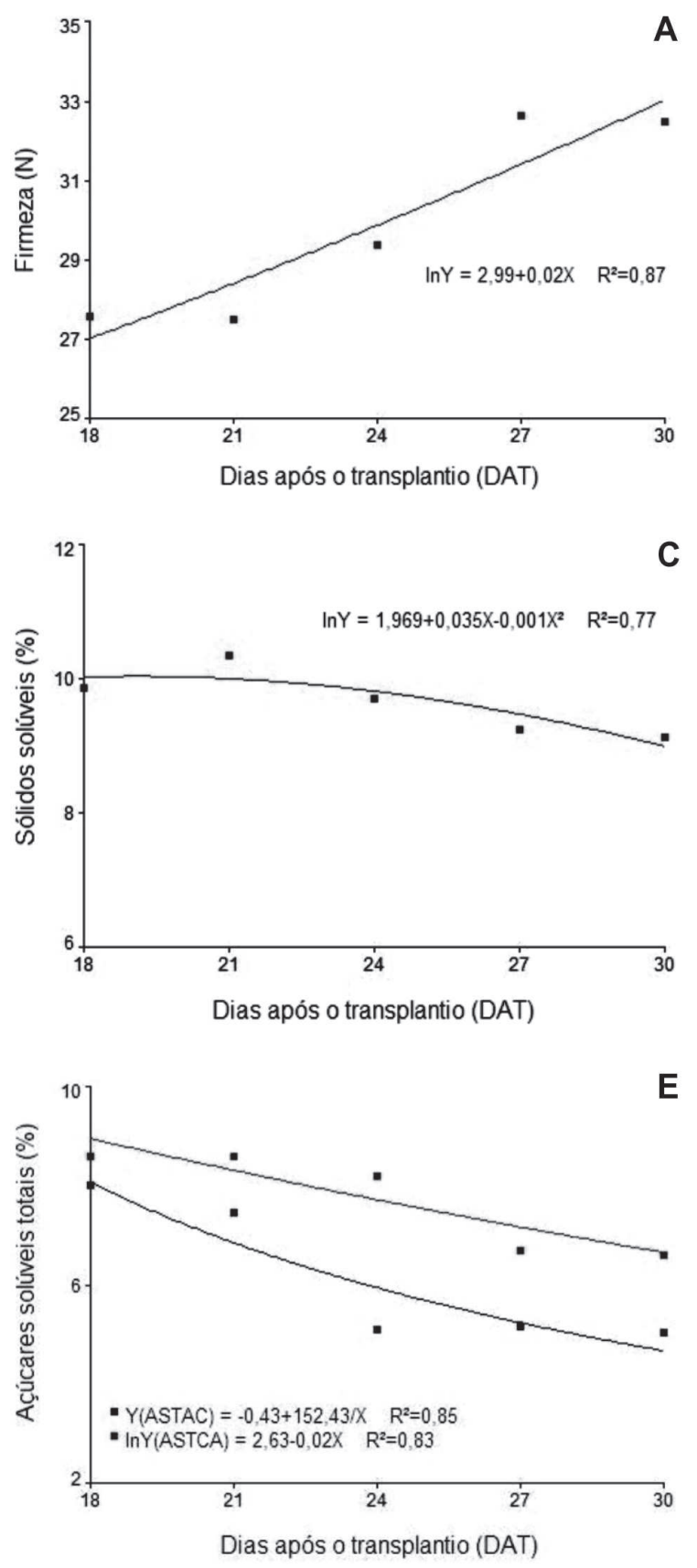

E
É importante observar que, com o aumento do número de dias de uso do agrotêxtil, o período de colheita pode ser prolongado, o que pode ser verificado pela maior firmeza de polpa nos frutos que foram protegidos com o agrotêxtil, por um período maior, em relação ao da testemunha (Figura 1A).

Foi pequena a variação dos valores de $\mathrm{pH}$, que decresceram com o aumento do tempo da permanência do agrotêxtil (Figura 5F), não havendo diferença significativa entre a testemunha e os demais tratamentos (Tabela 6). Estas pequenas variações, frequentemente encontradas na determinação de $\mathrm{pH}$, em fru-
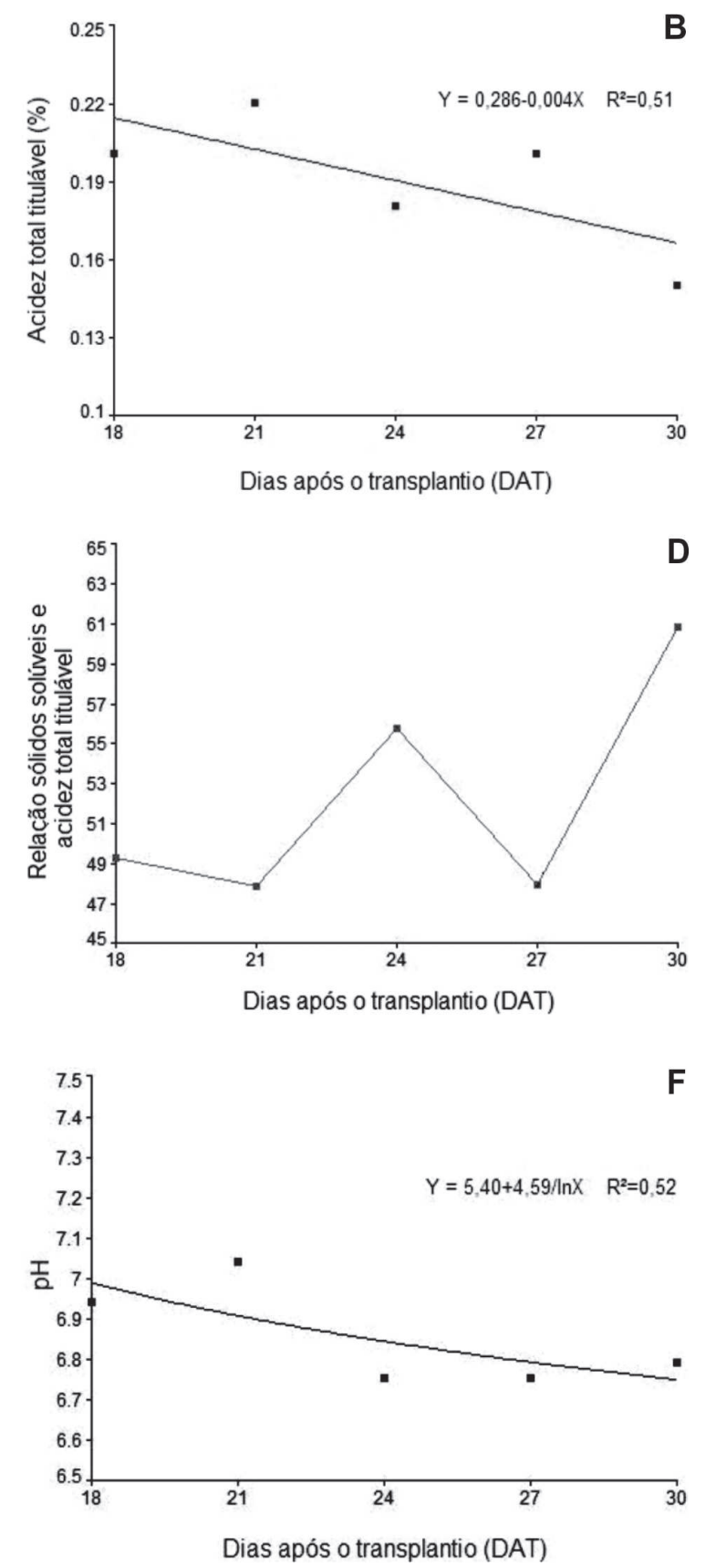

Figura 1. Firmeza da polpa (A), acidez titulável (B), sólidos solúveis (C), relação sólidos solúveis/acidez titulável (D), açúcares solúveis totais (E) e pH (F) de frutos de melão 'Acclaim' (AC) e 'Caribbean Gold' (CA) cultivados sob proteção de agrotêxtil em DAT. 
tos, podem ser explicadas pela capacidade tamponante de alguns ácidos (Chitarra \& Chitarra, 2005; Souza et al., 2008).

\section{CONCLUSÕES}

A produção total de frutos de melão não foi afetada para as plantas protegidas por até 30 dias após o transplantio.

O híbrido 'Caribbean Gold RZ' foi o mais produtivo para a exportação.

O híbrido ‘Acclaim' foi o mais produtivo para o mercado interno.

O aumento do tempo de permanência do agrotêxtil promoveu aumento da firmeza da polpa e redução da acidez total titulável e do $\mathrm{pH}$, para ambos os híbridos e, efeito quadrático para os sólidos solúveis, para o híbrido 'Caribbean Gold RZ'.

O aumento do tempo de permanência do agrotêxtil promoveu redução do teor de açúcares totais, para ambos os híbridos.

O híbrido 'Caribbean Gold RZ' apresentou maiores firmeza da polpa, acidez total titulável e teores de sólidos solúveis que o 'Acclaim'.

\section{REFERÊNCIAS}

Allen RG, Pereira LS, Raes D \& Smith (2006) Evapotranspiration del cultivo: guias para la determinación de los requerimientos de agua de los cultivos. Roma, FAO. 298p. (FAO Estudio Riego e Drenaje Paper, 56).

Alves RE, Pimentel CR, Maia CE, Castro EB de, Viana FM, Costa FV, Andrade GG de, Filgueiras HAC, Almeida JHS de, Menezes JB, Costa JG \& Pereira L de SE (2000) Manual de melão para exportação. Brasilia, Embrapa. 51p.

Barros Junior AP, Granjeiro LC, Bezerra Neto F, Negreiros MZ, Souza JO, Azevedo PE \& Medeiros DC (2004) Cultivo da alface em túneis baixos de agrotextil. Horticultura Brasileira, 22:801-803.

Braga Sobrinho R, Guimarães JA, Mesquita ALM, Chagas MCM, Fernandes OA, Freitas JAD (2003) Monitoramento de pragas na produção integrada do meloeiro. Fortaleza, Embrapa Agroindústria Tropical, 25p. (Documentos, 69)

Chitarra MIF \& Chitarra AB (2005) Pós-colheita de frutos hortaliças: fisiologia e manuseio. $2^{\mathrm{a}}$ ed. Lavras, UFLA. 785p.

Dantas DJ, Mendonça V, Nunes GHS, Guimarães IP \& Dantas DJ (2011) Avaliação da produção e qualidade de híbridos de melão cantaloupe. Revista verde de Agroecologia e Desenvolvimento Sustentável, 6:132-136.

Dias RCS, Silva CMJ, Costa ND, Faria CMB, Lima MAC, Santos MH, Soares JM, Haji FP, Assis JS \& Paiva LB (2006) Desempenho de melão tipo amarelo em diferentes coberturas de solo e sob cultivo temporariamente protegido no Vale do São Francisco. In: XLVI Congresso Brasileiro de Olericultura, Goiânia. Anais, Horticultura Brasileira. p.165-168.

Duarte TS \& PEIL RMN (2010) Relações fonte: dreno e crescimento vegetativo do meloeiro. Horticultura Brasileira, 28:271-276.

Dull GG, Leffler RG, Birth GS \& Smittle DA (1992) Instrument for nondestructive measurement of soluble solids in honeydew melon. Transactions of the ASAE, 35:735-737.
Gualberto R, Braz LT \& Banzatto DA (2002) Produtividade, adaptabilidade e estabilidade fenotípica de cultivares de tomateiro sob diferentes condições de ambiente. Pesquisa Agropecuária Brasileira, 37:81-88.

Ibarra L, Flores J \& Diaz-Pérez JC (2001) Growth and yield of muskmelon in response to plastic mulch and row covers. Scientia Horticulturae, 87:139-145.

Ibarra-Jiménez L, Brondo JMF, Herrera SAR, López AR, Pérez JCD, Mendoza JLH \& Larios JF (2000) Influencia del acolchado y microtúnel em el microclima y redimiento de pimiento morrón y melón. Revista Fitotecnia Mexicana, 23:01-15.

Instituto Adolfo Lutz (1985) Normas analíticas: métodos químicos e físicos para análise de alimentos. $3^{\mathrm{a}}$ ed. São Paulo, IMESP. 533p.

Jandel Scientific (1991) Table Curve: curve fitting software. Corte Madera, Jandel Scientific. 280p.

Long RL, Walsh KB, Midmore DM \& Rogers G (2004) Source-sink manipulation to increase melon (Cucumis melo) fruit biomass and soluble sugar content. Australian Journal of Agricultural Research, 55:1241-1251.

Medeiros JF, Santos SCL, Câmara MJT \& Negreiros MZ (2007) Produção de melão Cantaloupe influenciado por coberturas do solo, agrotêxtil e lâminas de irrigação. Horticultura Brasileira, 25:538-543.

Medeiros EV de, Serafim ECS, Granjeiro LC, Sobrinho JE, Negreiros MZ \& Sales Júnior R (2008) Influência do agrotextil sobre a densidade populacional de monosporascus cannonballus em solo cultivado com melancia (citrullus lanatus) Ciência e Agrotecnologia, 32:797803 .

Medeiros DC, Medeiros JF, Pereira FAL, Souza RO \& Souza PA (2011) Produção e qualidade de melão cantaloupe cultivado com água de diferentes níveis de salinidade. Revista Caatinga, 24:92-98.

Melo DM, Castoldi R, Charlo HCO, Galatti FZ \& Braz LT (2012) Produção e qualidade de melão rendilhado, sob diferentes substratos em cultivo protegido. Revista Caatinga, 25:58-66.

Menezes JB, Filgueiras HAC, Alves RE, Maia CEJ, Andrade GG, Almeida JHS \& Viana FMP (2000) Características de melão para exportação. In: Filgueiras HAC Melão pós-colheita. Brasilia. Embrapa. Spi/Frutas do Brasil. p.23-41. (Frutas do Brasil, 10)

Moreira RS, Melo AMT, Purqueiro LFV, Trani PE \& Narita N (2009) Melão (Cucumis melo L.). Disponível em: < http:// www.infobibos.com/Artigos/2009_3/melao/index.htm>. Acessado em: 20 abril de 2010 .

Paes RA (2011) Cultivo de melão com agrotêxtil combinado com Mulch plástico. Tese de Doutorado. Universidade Federal Rural do SemiÁrido, Mossoró. 86p.

Pereira VC, Sobrinho JE, Oliveira AD de, Vieira RYM, Melo TK, Melo SB \& Silva FG (2010) Influência dos eventos El Niño e La Niña na precipitação pluviométrica de Mossoró-RN. In: Congresso Brasileiro de Meteorologia, XVI. AAmazônia e o Clima Global. Belém, 2010, Anais. Disponível em <http://www.cbmet2010.com/anais/artigos/ 60_46462.pdf.> Acessado em 08 novembro 2011.

Santos HG, Jacomine PKT, Anjos LHC, Oliveira VA, Oliveira JB, Coelho MR, Lumbreras JF \& Cunha TJF (2006) Sistema brasileiro de classificação de solos. $2^{\mathrm{a}}$ ed. Rio de Janeiro, Embrapa-Solos. 306p.

Souza PA, Finger FL, Alves RE, Puiatti M, Cecon PR \& Menezes JB (2008) Conservação pós-colheita de melão Charentais tratado com 1MCP e armazenado sob refrigeração e atmosfera modificada. Horticultura Brasileira, 26:464-470.

Yemn EW \& Willis AJ (1954) The estimation of carbohydrate in plant extracts by anthrone. The Biochemical Journal London, 57:508-514. 